\title{
Empyema of the gallbladder due to Haemophilus parahaemolyticus, with a brief review of its role as a pathogen
}

\author{
MICHAEL PARSONS AND IRWIN FARIS \\ From the Department of Bacteriology and Department of Surgical Studies, Middlesex Hospital Medical \\ School, London
}

SYNOPSIS A case of empyema of the gallbladder caused by Haemophilus parahaemolyticus is reported. This is believed to the the first report of such an infection. The literature relating to pathogenicity of this organism is reviewed.

It used to be thought that apart from Haemophilus influenzae organisms of the Haemophilus group were only rarely pathogenic to man. But this idea has been revised. For example, Haemophilus parainfluenzae has been found to be a cause of meningitis, endocarditis, and occasionally of other infections (Sanders, Russell, and Gilliam, 1968; Gordon and Love, 1970; Hable, Logan, and Washington, 1971), and since the first account of Haemophilus aphrophilus (Khairat, 1940) it has become recognized as a cause of endocarditis and brain abscess (Speller, Prout, and Saunders, 1968). Nevertheless it remains true that the organisms of this group other than $H$. influenzae command little attention as possible pathogens. In particular the haemolytic varieties tend to be discounted (Turk and May, 1967).

We report here a case of empyema of the gallbladder due to $H$. parahaemolyticus.

\section{Case Report}

A 40-year-old policeman was admitted for elective cholecystectomy following two attacks of pain beneath the right costal margin. He had previously been in good health apart from an attack of enteric fever 20 years before. Oral cholecystography showed a common bile duct of normal calibre but no filling of the gallbladder.

At operation the gallbladder was embedded in the liver. While being freed it was inadvertently ruptured and thick pus escaped. This was immediately aspirated into a syringe and sent for culture. There were stones in the gallbladder but none in the common duct.

His subsequent course was uneventful and he was discharged on the eleventh postoperative day.

Received for publication 31 May 1973.

\section{Laboratory Findings}

Gram staining of the pus showed many small $\vec{\varphi}$ pleomorphic Gram-negative rods. The bile was cultured aerobically and anaerobically on Columbia agar (Oxoid) with 5\% horse blood added. After 18 hours' incubation it produced a pure growth of small grey beta-haemolytic colonies which were facultatively anaerobic. Growth was not improved in an atmosphere of $10 \% \mathrm{CO}_{2}$. There was no growth on CLED medium (Oxoid) or nutrient agar (Oxoid). The colonies consisted of Gram-negative rods resembling those already seen. A viable count (Miles and Misra) performed within three hours of operation showed $5 \times 10^{6}$ organisms $/ \mathrm{ml}$ of bile. On nutrient agar (Oxoid) there was abundant growth round discs containing $\mathrm{V}$ and $\mathrm{X}+\mathrm{V}$ factors (Mast) but none around that containing $\mathrm{X}$ factor only. This was repeated on subculture from around the $\mathrm{V}$ factor disc. The organism was non-motile, indole 윽 negative, and reduced nitrates. It was therefore considered to be $H$. parahaemolyticus. (We are grateful to Mr L. R. Hill of the National Collection N of Type Cultures for confirming the identification.) Because of the history of enteric fever the bile was $N$ cultured in Selenite F and on DCA (Oxoid) but no salmonella or other organism was isolated.

Histology of the gallbladder showed marked $c$ inflammatory thickening of the wall, with gross $\stackrel{\mathbb{D}}{\stackrel{D}{ }}$ muscle hypertrophy and intramural diverticula. The $\stackrel{\oplus}{+}$ stones were of cholesterol.

\section{Discussion}

The existence of Haemophilus bacteria which are haemolytic on blood agar and require $\mathrm{V}$ but not $\mathrm{X}$ as 
growth factor was known before 1953 but it was then that Pittman proposed the name $H$.parahaemolyticus, by which they have since been known (Pittman, 1953). She said then: 'The bacteria are associated frequently with acute pharyngitis and occasionally cause subacute endocarditis.' But in fact there is little firm information about their status as pathogens.

Lichty (1937) described subacute bacterial endocarditis in a 14-year-old boy due to an haemolytic Haemophilus organism which required $V$ but not $\mathrm{X}$ factor. However in a brief review of Haemophilus endocarditis Gordon and Love (1970) mention no cases due to $H$. parahaemolyticus, nor have we found any others.

In a study of 100 patients with sore throat, Branson (1968) found $H$. parahaemolyticus in 30 of them, but she also found it in $18 \%$ of controls. Moreover Sims (1970) reports isolating it from just under one third of all oral clinical specimens, so its significance in this respect is hard to assess.

Apart from these the only reported example of $H$. parahaemolyticus as a pathogen appears to be the case of Hable et al (1971) in which it caused periorbital septicaemia and cellulitis in a 1-year-old baby.

The present case is interesting both for the organism and for its presence in this site. Organisms cultured from the bile are usually Gram-negative intestinal bacteria or streptococci, with occasional staphylococci. In three series (Scott and Khan, 1967; Flemma, Flint, Osterhout, and Shingleton, 1967; Robson, Bogart, and Heggers, 1970) in which positive cultures were obtained from 98 patients in all, no haemophili were found. They may rarely be isolated from the digestive tract and occasionally are pathogenic there. Branson (1967) reports a case of $H$. influenzae appendicitis, with references to others, and mentions the isolation of $H$. parainfluenzae from an appendix.

How the organism reached this patient's gallbladder is not certain. There may have been a transient bacteraemia, as is known with other upper respiratory tract commensals, and the bacteria came through the gallbladder wall. This would be in accord with the current theory that bacteria in the bile tend to get there from the bloodstream through the wall rather than by ascending from the gut
(Scott, 1971). But culture of the wall after washing in Ringer's solution and homogenizing yielded no growth in this case, so the organism may have originated in the gut.

As mentioned, there have been very few previous reports of $\boldsymbol{H}$. parahaemolyticus as a pathogen and none of it as a pyogenic organism. This is probably due to failure both to isolate it and to appreciate its significance once isolated. Culture must be on a medium which supports its growth, with a selective technique such as a V factor disc to enhance it. Haemolysis must be sought using horse or rabbit blood; human and sheep blood inhibit growth of haemolytic haemophili (Branson, 1968). Furthermore, the attitude which dismisses the organism when isolated as merely a commensal should be revised on the evidence of this and the other cases quoted.

We are grateful to Professor L. P. LeQuesne under whose care the patient was for permission to report this case.

\section{References}

Branson, D. (1967). Isolation of Haemophilus influenzae from appendix and incision. Amer. J. clin. Path., 47, 643-645.

Branson, D. (1968). Bacteriology and clinical significance of hemolytic Haemophilus in the throat. Appl. Microbiol., 16, 256-259.

Flemma, R. J., Flint, L. M., Osterhout, S., and Shingleton, W. W. (1967). Bacteriologic studies of biliary tract infection. Ann. Surg., 166, 563-572.

Gordon, A. M., and Love, W. C. (1970). Endocarditis due to Haemophilus parainfluenzae. J. med. Microbiol., 3, 550-554.

Hable, K. A., Logan, G. B., and Washington, J. A., II (1971). Three Haemophilus species: pathogenic activity. Amer. J. Dis. Child., 121, 35-37.

Khairat, O. (1940). Endocarditis due to a new species of Haemophilus. J. Path. Bact., 50, 497-505.

Lichty, J. A., Jr. (1937). Subacute bacterial endocarditis due to a hemolytic para-influenza bacillus. Amer. J. Dis. Child., 54, 1311-1319.

Pittman, M. (1953). A classification of the hemolytic bacteria of the genus Haemophilus. J. Bact., 65, 750-751.

Robson, M. C., Bogart, J. N., and Heggers, J. P. (1970). An endogenous source for wound infections based on quantitative bacteriology of the biliary tract. Surgery, 68, 471-476.

Sanders, D. Y., Russell, D. A., and Gilliam, C. F. (1968). Isolation of Haemophilus species from abscesses in two children. Pediatrics, 42, 683-684.

Scott, A. J. (1971). Bacteria and disease of the biliary tract. Gut, 12, $487-492$.

Scott, A. J., and Khan, G. A. (1967). Origin of bacteria in bileduct bile. Lancet, 2, 790-792.

Sims, W. (1970). Oral Haemophili. J. med. Microbiol., 3, 615-625.

Speller, D. C. E., Prout, B. J., and Saunders, C. F. (1968). Subacute bacterial endocarditis caused by a micro organism resembling Haemophilus aphrophilus. J. Path. Bact., 95, 191-198.

Turk, D. C., and May, J. R. (1967). Haemophilus influenzae: Its Clinical Importance. English Universities Press, London. p. 12. 